\title{
A Wide-Range and Calibration-Free Spectrometer Which Combines Wavelength Modulation and Direct Absorption Spectroscopy with Cavity Ringdown Spectroscopy
}

\author{
Zhen Wang, Yanjun Du, Yanjun Ding and Zhimin Peng * \\ State Key Laboratory of Power Systems, Department of Energy and Power Engineering, Tsinghua University, \\ Beijing 100084, China; wangzhen16@mails.tsinghua.edu.cn (Z.W.); duyanjun@mail.tsinghua.edu.cn (Y.D.); \\ dyj@tsinghua.edu.cn (Y.D.) \\ * Correspondence: apspect@tsinghua.edu.cn; Tel.: +86-134-8871-1597
}

Received: 22 December 2019; Accepted: 16 January 2020; Published: 21 January 2020

\begin{abstract}
A wide-range, calibration-free tunable diode laser spectrometer is established by combining wavelength modulation and direct absorption spectroscopy (WM-DAS) with continuous wave cavity ringdown spectroscopy (CW-CRDS). This spectrometer combines the benefits of absolute concentration measurements, wide range, and high speed, using WM-DAS with enhanced noise reduction in CW-CRDS. The accurate baseline ringdown time, $\tau_{0}$, is calculated by the absorption peak (measured by WM-DAS) and the ringdown time containing gas absorption information (measured by CW-CRDS at the center wavelength of the spectral line). The gas concentration is obtained without measuring $\tau_{0}$ in real time, thus, greatly improving the measuring speed. A WM-DAS/CW-CRDS spectrometer at $1.57 \mu \mathrm{m}$ for $\mathrm{CO}$ detection was assembled for experimental validation of the multiplexing scheme over a concentration ranging from $4 \mathrm{ppm}$ to $1.09 \%(0.1 \mathrm{MPa}, 298 \mathrm{~K})$. The measured concentration of $\mathrm{CO}$ at $6374.406 \mathrm{~cm}^{-1}$ shows that the dynamic range of this tunable diode laser absorption spectrometer is extendable up to five orders of magnitude and the corresponding precision is improved. The measurement speed of this spectrometer can extend up to $10 \mathrm{~ms}$, and the detection limit can reach $35 \mathrm{ppb}$ within $25 \mathrm{~s}$.
\end{abstract}

Keywords: continuous wave cavity ringdown spectroscopy; wavelength modulation and direct absorption spectroscopy; $\mathrm{CO}$; calibration free; wide range

\section{Introduction}

Tunable laser diode absorption spectroscopy (TDLAS) [1-3] has the advantages of being noncontact, fast response, and wavelength selective. The direct absorption spectroscopy (DAS) [4-6] in TDLAS has a clear physical concept and is easy to operate, which is frequently used to quantify concentration, temperature, and other parameters of gases. DAS has also been widely used in the case of high concentrations and strong absorption environments (absorbance 0.01 to $\sim 1$ ). For trace gas monitoring or weak absorption line measurements (absorbance $<10^{-3}$ ), techniques with a higher signal-to-noise ratio (SNR) are used, such as cavity-enhanced absorption spectroscopy (CEAS) [7-9] or continuous wave cavity ringdown spectroscopy (CW-CRDS) [10-12].

In some environments, the gas concentration can change from a trace to a high level in a matter of minutes and occasionally fluctuates violently. For example, when monitoring the concentration of water in the upper atmosphere on a moving aircraft, it can range from $\sim 1 \mathrm{ppm}$ to $1 \%$ and fluctuate sharply as the aircraft passes through the clouds [13]. In the atmospheric, laminar and non-premixed $\mathrm{CH}_{4} /$ air model flames, the concentration of $\mathrm{CO}$ at different heights in the flame ranges from $\sim 1 \mathrm{ppm}$ to 
$4 \%$ [14]. The concentration of engine exhaust gases (e.g., $\mathrm{NO}$ and $\mathrm{CO}$ ) in a single internal combustion engine cycle can range from $\sim 1 \mathrm{ppm}$ to $0.3 \%$ (NO) and $\sim 1 \mathrm{ppm}$ to $4 \%(\mathrm{CO})$ [15]. There is also quite a large difference in the radial profile of the $\mathrm{HO}_{2}$ concentrations throughout the plasma effluent in an atmospheric pressure plasma jet [16]. In these cases, such a wide range single method (DAS, CW-CRDS, or CEAS) for fast measurements of gas concentration is difficult to achieve. Because of the weak signal and the short ringdown time at high concentrations, CW-CRDS requires higher gain detectors and faster data sampling rates [17-19]. Likewise, owing to the weak gas absorption at low concentrations, DAS needs a longer optical path [20] or stronger mid-infrared gas absorption lines which further require mid-infrared quantum cascade lasers [21] or interband cascade lasers [22]. One of the simplest solutions is to combine various methods, such as the DAS and wavelength modulation spectroscopy (WMS) [23-25]. By using the quantitative results of DAS to calibrate the WMS, the online measurement of water concentration over a wide range and with high precision can be realized [26]. The combination of CW-CRDS and laser-induced fluorescence (LIF) facilitates the real-time and high-precision measurement of $\mathrm{NO}_{x}$ in the atmosphere [27]. The complementary nature of CEAS and CW-CRDS methods also facilitates the real-time and high-precision detection of $\mathrm{N}_{2} \mathrm{O}_{5}$ in the atmosphere [28]. Therefore, this paper focusses on the combination of CW-CRDS and DAS. Simultaneously, the wavelength modulation and direct absorption spectroscopy (WM-DAS) [29-31] method, which is based on sinusoidal modulation and fast Fourier transform (FFT) analysis, proposed by our group recently, further improves the accuracy of DAS. With this method, the root mean square error (RMSE) of spectral fitting reaches $\sim 3 \times 10^{-5}$ [30] and, then, the detection limit of WM-DAS can reach $\sim 3 \times 10^{-9} \mathrm{~cm}^{-1}$ which is realized by using a long optical path cell of $\sim 100 \mathrm{~m}$ (e.g., Herriott cell [32]). In this way, WM-DAS obtains a large intersection with the measurement range of CW-CRDS. Thus, a wide range of measurement is easily obtained by the combination of WM-DAS and CRDS. This large intersection area between the two methods makes it possible to obtain the calibration-free baseline ringdown time.

This paper describes a simple method based on WM-DAS and CW-CRDS to construct a wide-range and calibration-free spectrometer for measuring gas concentration. The measuring range and accuracy of the proposed spectrometer were analyzed theoretically and verified by measuring $C O\left(6374.406 \mathrm{~cm}^{-1}\right)$ in various concentrations at room temperature and normal atmospheric pressure. Merging the benefits of WM-DAS (fast response and calibration free) with CW-CRDS (high precision), a wide measuring range and a large intersection area between the two methods are obtained. In this intersection area, the accurate baseline ringdown time, $\tau_{0}$, is calculated by using the peak absorbance (measured by WM-DAS) and the ringdown time containing gas absorption information (measured by CW-CRDS at the center wavelength of the spectral line). In this fashion, free calibration of $\tau_{0}$ is realized and the connection between the two methods is established through $\tau_{0}$. Moreover, the measuring speed and the detection limit of this spectrometer are further improved.

\section{Experimental Systems}

The system schematics for CW-CRDS [10-12] and WM-DAS [29,30] are shown in Figure 1. The light source, in both the cases, is a DFB laser which has a continuous wavelength ranging from 1566 to $\sim 1570 \mathrm{~nm}\left(6369\right.$ to $\left.\sim 6386 \mathrm{~cm}^{-1}\right)$. The laser was tuned by changing the temperature and the current. The laser beam propagated through an optical isolator to reduce the optical feedback to the diode laser and, then, divided into four beams. One of the beams was focused on an acousto-optic modulator to generate the first-order beam that was, subsequently, focused into the ringdown cavity. The other three beams entered the Herriott cell [32], the wavelength meter, and the etalon, respectively. The free spectral region of the etalon is $1.5 \mathrm{GHz}\left(\sim 0.05 \mathrm{~cm}^{-1} @ 6381 \mathrm{~cm}^{-1}\right)$ and the measurement accuracy of the wavelength meter is $0.2 \mathrm{ppm}\left(0.0013 \mathrm{~cm}^{-1} @ 6381 \mathrm{~cm}^{-1}\right)$.

The optical cavity (length, $50 \mathrm{~cm}$ ) was formed by a pair of high-reflectivity (curvature, $1 \mathrm{~m}$ and $\mathrm{R}$ $>0.999975$ at $1530 \mathrm{~nm}$ ) mirrors. The piezoelectric transducer (PZT) was used to scan the cavity length. The magnitude and rate at which the cavity was modulated were determined by the desired quality of 
the resulting spectrum. Light was collected after the second cavity mirror using a lens and an InGaAs avalanche photodetector (Thorlabs, Inc., Newton, USA). When the buildup reached the preset trigger level of $1.5 \mathrm{~V}$, the digital delay generator (DDG) sent out a pulse to the radiofrequency (RF) source that de-energized the acousto-optic modulator (AOM); thus, shutting off the light from going into the cavity. The data acquisition (DAQ) card, then, simultaneously collected the pulse signals and the ringdown signals and processed them using LabVIEW software in real time. The sampling rate was $20 \mathrm{MHz}$ and the ringdown event sampling duration was $200 \mu \mathrm{s}$. The data analysis program ascertained the position of the rising edge of the pulse signal as the starting point and removed the initial $0.2 \mu$ s from the top of the ringdown curve while retaining the rest of the signal. The system used a fast fitting algorithm [33] to calculate the ringdown time measured at about $100 \mathrm{~Hz}$.

The Herriott cell was formed by a pair of flat-concave mirrors. The distance between the two mirrors was $1.05 \mathrm{~m}$, and the effective optical path was about $120 \mathrm{~m}$. The emergent light was collected using an InGaAs photodetector, and the signals from the photodetector were transmitted to the DAQ card and, simultaneously, processed by the LabVIEW program. The relative laser wavelength was measured by the etalon.

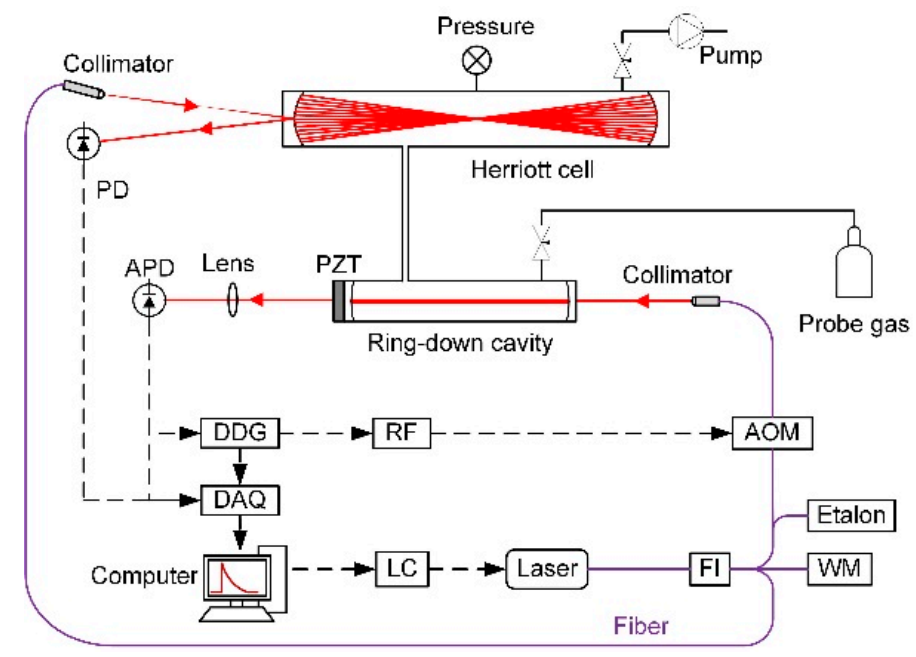

Figure 1. System schematics for the continuous wave cavity ringdown spectroscopy (CW-CRDS) and wavelength modulation and direct absorption spectroscopy (WM-DAS) methods. LC, laser current and temperature controller; FI, fiber isolator; AOM, acousto-optic modulator; PD, photodiode; APD, avalanche photodiode; DDG, digital delay generator; PZT, piezoelectric transducer; WM, wavelength meter; RF, radiofrequency; and DAQ, data acquisition.

\section{Methods}

\subsection{WM-DAS}

On the basis of DAS [4-6], the WM-DAS uses high-frequency sinusoidal modulation and FFT to filter noises to precisely recover the absorption spectrum [29]. In this technique, the laser wavelength is scanned periodically by modulating the laser current by a sinusoidal signal, and the laser is received by the detector after passing through the gas absorption cell. The light intensity of the laser can be defined by the following formula:

$$
I(x)=\sum_{k=0}^{\infty} A_{k} \cos [k(\arccos x-\eta)] \pm B_{k} \sin [k(\arccos x-\eta)]
$$


where $k=0,1,2, \ldots,-1 \leq x \leq 1, A$ and $B$ are the real and imaginary parts of the Fourier coefficients of the characteristic frequencies, and $\eta$ is the initial phase angle. The relative wavelength of the laser can be defined by the following formula:

$$
v(x)=v_{0}+a_{1} x+a_{2}\left[\left(2 x^{2}-1\right) \cos \varphi_{2} \pm 2 x \sin \varphi_{2} \sqrt{1-x^{2}}\right]
$$

where $v_{0}$ is the laser center wavelength. In Equations (1) and (2), "-" and " + " are used in the left $(V 1 V 2)$ and right $(V 1 V 3)$ periods, respectively [29] The coefficients $\left(a_{1}, a_{2}, \eta\right.$, and $\left.\varphi_{2}\right)$ can be obtained by measuring the relative wavelengths of the laser using an etalon. Through the above formula, the transmitted light intensity $\left(I_{t}\right)$ with gas absorption and the transmitted light intensity $\left(I_{0}\right)$ without gas absorption can be obtained, and the absorbance, $\alpha(v)$, can be obtained from the Beer-Lambert's law:

$$
\alpha(v)=-\ln \left[\frac{I_{t}(v)}{I_{0}(v)}\right]=P S(T) X L \varphi(v)
$$

where $P$ is pressure, $S$ is the line intensity, $T$ is temperature, $X$ is the mole fraction of the gas under study, $L$ is the optical path, and $\varphi(v)$ is the line shape function. At atmospheric pressure, $\varphi(v)$ can be described by the Voigt line shape [34].

Figure $2 \mathrm{a}, \mathrm{b}$ shows the originally transmitted signals and the recovered spectrum at $6374.406 \mathrm{~cm}^{-1}$ for a CO concentration of 1010 ppm. As shown in Figure 2a, only the harmonics of characteristic frequencies are extracted to reconstruct the signal of the transmitted light, and the noises from other frequencies $(\sim 19.4 \mathrm{kHz})$ can be effortlessly removed. As shown in Figure $2 \mathrm{~b}$, even if the effective optical path is $120 \mathrm{~m}$, the root mean square error (RMSE) of the spectrum is about $1.3 \times 10^{-4}\left(2.72 \times 10^{-6} \mathrm{~cm}^{-1}\right)$ at room temperature and normal atmospheric pressure and is smaller than that reported in the literature [26], which proves that the WM-DAS method has high accuracy.
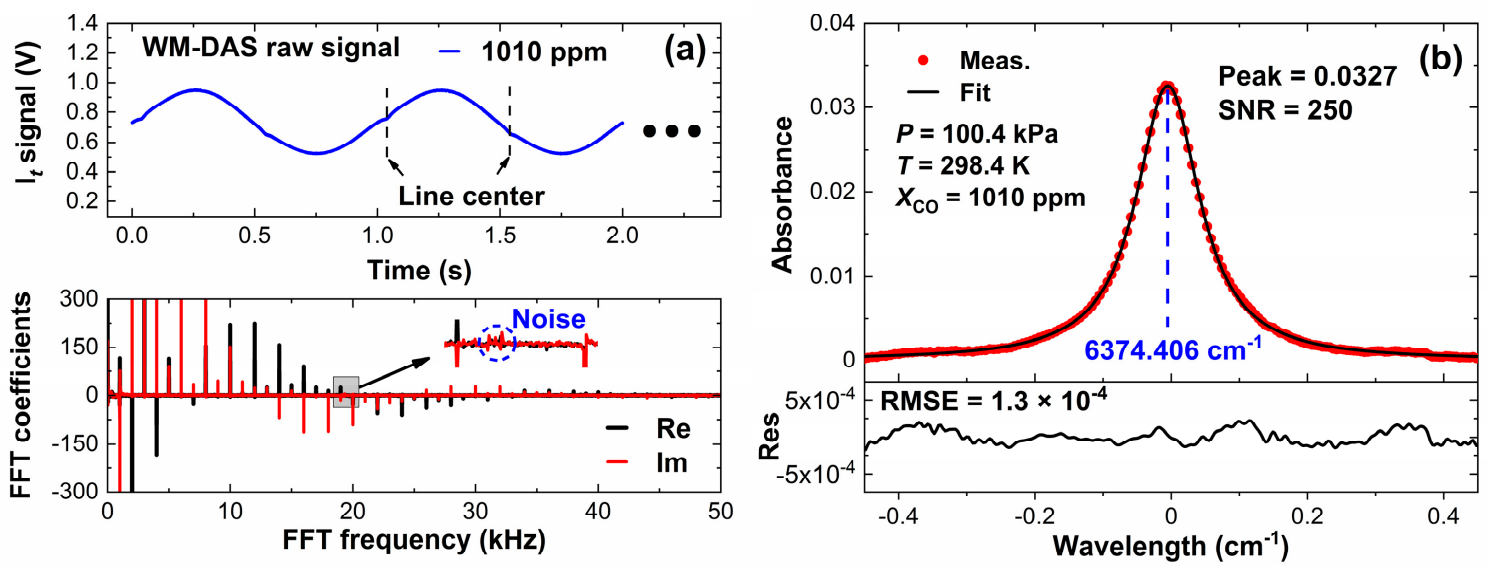

Figure 2. (a) Original WM-DAS signal and the corresponding fast Fourier transform (FFT) spectrum and $(\mathbf{b})$ recovered absorbance of $\mathrm{CO}$.

\section{2. $C W-C R D S$}

The CW-CRDS typically uses wavelength scanning or cavity length scanning to couple a laser mode with a cavity mode [10-12] (this paper uses cavity length scanning), then, the ringdown signal is collected and the corresponding ringdown time $(\tau)$ is calculated. The absorption coefficient $(\kappa)$ related to $\tau$ is [17-19]:

$$
\kappa(v)=\frac{1}{c}\left(\frac{1}{\tau(v)}-\frac{1}{\tau_{0}(v)}\right)=\operatorname{PS}(T) X \varphi(v)
$$

where, $c$ is the speed of light, $\tau_{0}$ is the ringdown time of the evacuated cavity which depends on the reflectivity $R$ of the cavity mirrors and losses including absorption by the dielectric coating and scattering on the surfaces and interiors of the mirrors. Herein, $P$ is pressure, $S$ is the line intensity, $T$ is 
temperature, $X$ is the mole fraction of the probe gas, and $\varphi(v)$ is the line profile. Since the $(1-R) / L$ term can be treated as the baseline, the absorption line profile can be attained by fitting the measured curve $1 / c \tau(v)$. Nonetheless, the measurement technique which scans the whole absorption line can take a long time in doing so, and hence is not suitable for online measurement. The measurement speed can be improved by fixing the laser wavelength at the center of the absorption line and measuring only the ringdown time at this wavelength. By fixing the laser wavelength, Equation (4) can be simplified to:

$$
\kappa_{v_{0}}=\frac{1}{c \tau}-\frac{1}{c \tau_{0}}
$$

where $\tau_{0}$ and $\tau$ are the ringdown times of the perturbing and the probe gas, respectively. In this way, the gas concentration can be determined without scanning the whole spectral line and the only parameter that needs to be calibrated is the baseline ringdown time $\tau_{0}$.

Figure 3 a shows the working principle of CW-CRDS using cavity length scanning at the center wavelength of the $\mathrm{CO}\left(6374.406 \mathrm{~cm}^{-1}\right)$ spectrum. The cavity modes can be coupled to the laser wavelength by PZT scanning (red). In order to facilitate the fast acquisition of ringdown time, the amplitude and rate of PZT were set at about $2 \mu \mathrm{m}$ and $100 \mathrm{~Hz}$. When the emergent light (blue) of the cavity reaches the threshold voltage $(\sim 1.5 \mathrm{~V})$, the DDG sends pulses (black) to turn off the AOM in order to obtain the ringdown signals. Figure $3 \mathrm{~b}$ shows the ringdown signals of the perturbing gas (blue) and the probe gas (red), and their corresponding ringdown time are $10.3 \mu$ s and $64.7 \mu$ s, respectively. The absorption coefficient, as calculated by the Equation (5), is $2.72 \times 10^{-6} \mathrm{~cm}^{-1}$, which equals the result of WM-DAS in Section 3.1.
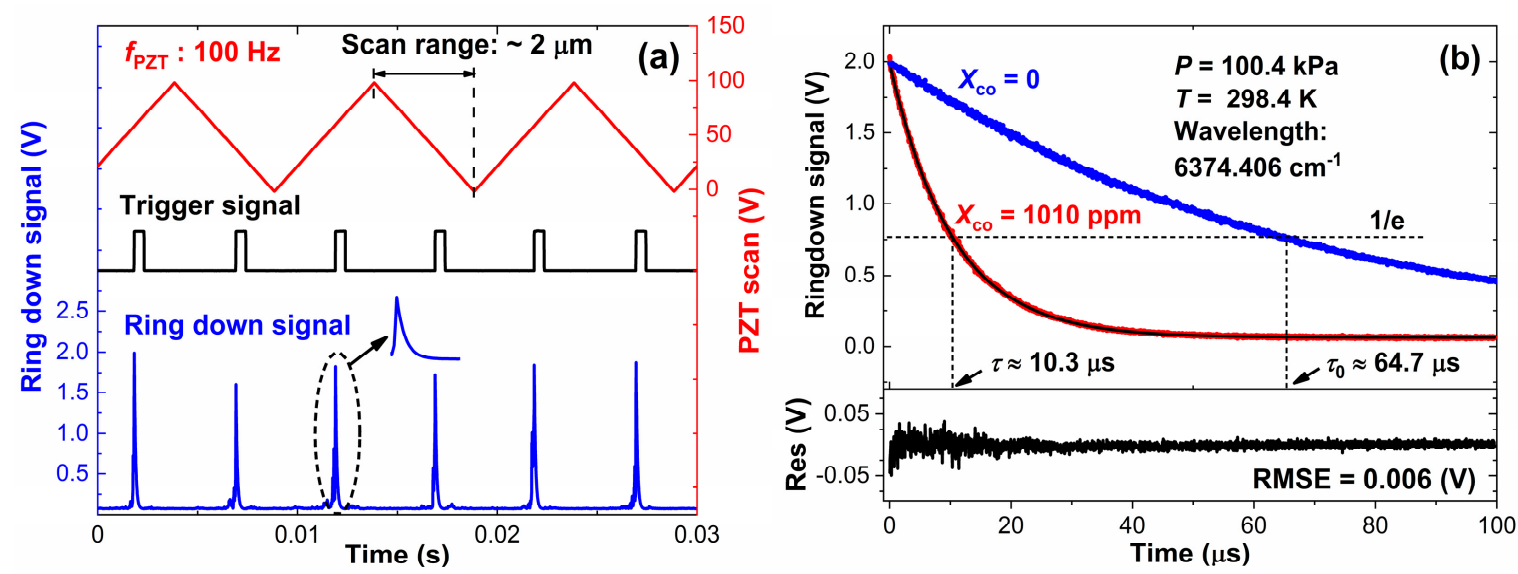

Figure 3. (a) Illustration of cavity length scanning, DDG trigger signal (black), light intensity (blue), PZT scan signal (red) and (b) ringdown signals of perturbing gas (blue) and probe gas (red) at $6374.406 \mathrm{~cm}^{-1}$.

\subsection{Calibration-Free Baseline Ringdown Time}

The above scheme, in Section 3.2, needs to measure the baseline ringdown time, $\tau_{0}$, which is not convenient enough for in situ measurements. Hence, a connection between the two (WM-DAS and CW-CRDS) gas chambers which have the same gas parameters are set up herein, following which, $\alpha=L \kappa$ can be obtained by combining Equation (3) with Equation (4). Thus, $\tau_{0}$ (at the center wavelength $v_{0}$ ) can be obtained:

$$
\frac{\alpha_{\max }}{L}=\frac{1}{c \tau}-\frac{1}{c \tau_{0}}
$$

where $\alpha_{\max }$ is the absorbance peak of the probe gas measured by WM-DAS and $\tau$ is the ringdown time containing gas absorption information measured at the central frequency $v_{0}$. According to Equation (6), the baseline ringdown time, $\tau_{0}$, can be calculated by $\alpha_{\max }$ and $\tau$. In this fashion, the baseline ringdown time, $\tau_{0}$, becomes calibration free and there is no need to take into account the small changes due to 
environmental factors. The measurement frequency of CW-CRDS can easily reach $100 \mathrm{~Hz}$, which is similar to previous reports in the literature [17-19].

\section{Analysis and Verification of the Measuring Range of the Proposed Spectrometer}

Figure 4 shows the range over which the $\mathrm{CO}$ concentrations were measured by the two methods (WM-DAS and CW-CRDS) at room temperature and normal atmospheric pressure. When the concentration is lower than $250 \mathrm{ppm}$, the absorption coefficient is found to be less than $6 \times 10^{-7} \mathrm{~cm}^{-1}$ and the equivalent absorbance is less than $7.2 \times 10^{-3}$. In keeping with the detection limit $\left(7 \times 10^{-5}\right.$ [29-31], at room temperature and normal atmospheric pressure) of WM-DAS, the SNR is only $\sim 103$. When the concentration is more than $5000 \mathrm{ppm}$, the absorption coefficient is over $1 \times 10^{-5} \mathrm{~cm}^{-1}$ and the SNR of WM-DAS with a $120 \mathrm{~m}$ Herriott cell lies close to 2000 . Strong absorption considerably weakens the emergent light from the ringdown cavity and reduces the ringdown time to less than $3.2 \mu$ s (the ringdown time of the evacuated cavity is $66.7 \mu \mathrm{s}$ ), which in turn, reduces the measurement accuracy of CW-CRDS. In order to circumvent this problem and improve the accuracy at high concentrations, CW-CRDS necessitates higher gain detectors and faster DAQ sampling rates. Likewise, at low concentrations, in order to improve the accuracy of WM-DAS measurements, it is necessary to consider a longer optical path (for instance a specially designed multiple reflection cell [35]) or to choose stronger mid-infrared gas absorption lines that require mid-infrared quantum cascade lasers [21] or interband cascade lasers [22]. Fortunately, the measuring range of WM-DAS with the $120 \mathrm{~m}$ Herriott cell has a large intersection with the CW-CRDS, and therefore the spectrometer established in this paper is the outcome of the process of combining the advantages of WM-DAS and CW-CRDS to achieve a single spectrometer having a wide and continuous range, as well as high precision for gas concentration measurement. Moreover, using Equation (6), the baseline ringdown time, $\tau_{0}$, can be calculated from the peak absorbance, $\alpha_{\max }$, measured by WM-DAS and the ringdown time, $\tau$, which contains gas absorption information as measured by CW-CRDS in the 250-5000 ppm range.

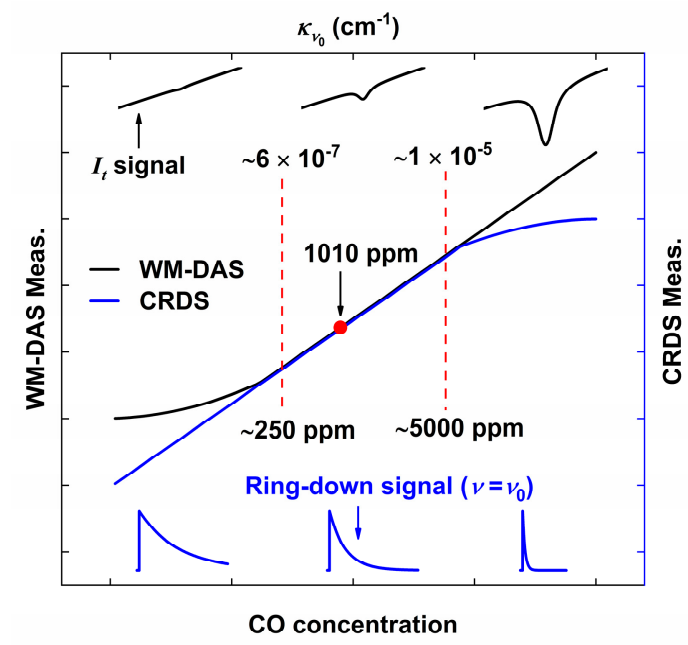

Figure 4. Relationships between ringdown signals at $v_{0}$, emergent light signals, absorption coefficient and concentration of $\mathrm{CO}$.

Two different concentrations of CO (1.09\% and $101 \mathrm{ppm})$ were used to verify the relationships between ringdown signals at $v_{0}$, emergent light signals, absorption coefficient, and concentration of $\mathrm{CO}$, as shown in Figure 5. Figure 5a shows the transmitted light intensity of $\mathrm{CO}$ in different concentrations measured by WM-DAS, from which we can note that the absorption for 101 ppm is very weak and almost submerged by noise. However, the characteristic frequencies $(1 \mathrm{kHz}, 2 \mathrm{kHz}, \ldots)$ and noises can still be distinguished by the FFT spectrum as shown in Figure 5b. The absorbance of $1.09 \%$ is very strong and the non-zero light intensity at the central wavelength indicates that the WM-DAS can measure a higher concentration (about 5\%). Figure 6a,b shows the recovery absorbance of $1.09 \%$ and 
101 ppm, wherein the minimum value of RMSE can reach up to $7.8 \times 10^{-5}$ at a peak absorbance of $0.32 \%$. Due to the wide wavelength range $\left( \pm 0.45 \mathrm{~cm}^{-1}\right)$ and the minor fluctuations of $\mathrm{CO}$ concentration at atmospheric pressure, the RMSE becomes slightly larger than that measured at lower pressures [30]. Therefore, the SNR in the spectrum of $1.09 \%$ is about 1760 less than the theoretical value shown in Figure 4. The experimental results show that the SNR in the spectrum of $101 \mathrm{ppm}$ is $\sim 42$, and for $250 \mathrm{ppm}$ it is $\sim 104$, which is consistent with Figure 4 . In the range of $250 \mathrm{ppm}$ to $1.09 \%$, the SNR is suitable enough for gas concentration measurement, displaying the wide measurement range and high accuracy of WM-DAS.
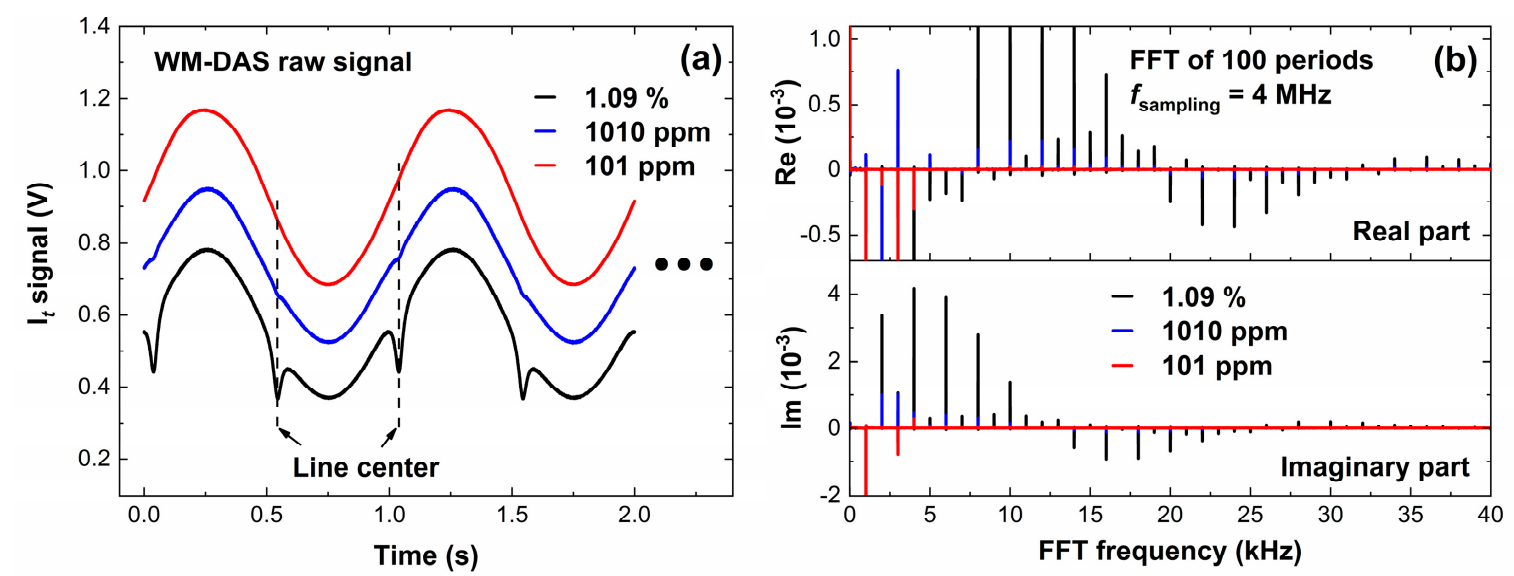

Figure 5. (a) Original signals of the transmitted light intensity at different concentrations measured by WM-DAS and (b) FFT spectrum of different concentrations.
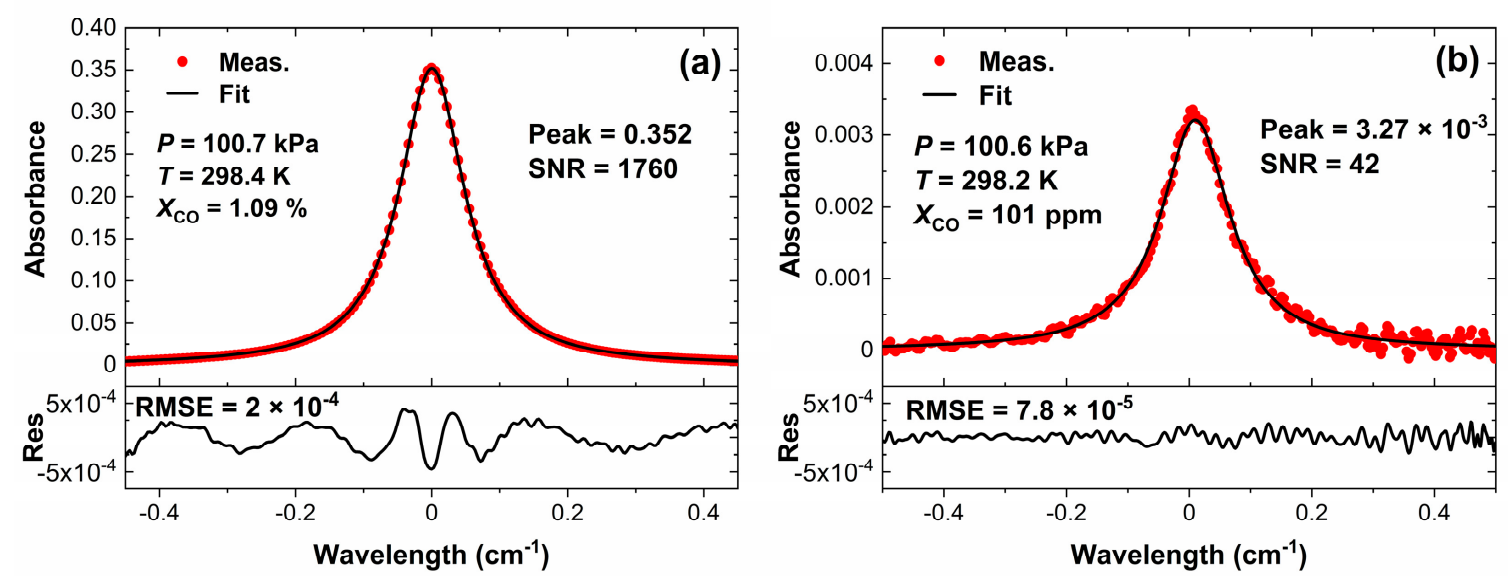

Figure 6. Restored absorbance at different concentrations of CO: (a) Concentration of $1.09 \%$ and (b) concentration of $101 \mathrm{ppm}$.

The experimental conditions for CW-CRDS are the same as those for WM-DAS. As shown in Figure $7 \mathrm{a}$, the ringdown time is only $1.12 \mu \mathrm{s}$ at high concentration $(1.09 \%)$ and the maximum light intensity of the ringdown curve is only $0.6 \mathrm{~V}$. At low concentration (101 ppm), the light intensity can reach up to $4 \mathrm{~V}$ and the ringdown time is approximately $43.9 \mu \mathrm{s}$. Figure $7 \mathrm{~b}$ normalizes the ringdown curves in Figure 7a, where the RMSE at high concentration (1.09\%) is much larger and is about four times that at low concentration (101 ppm). Therefore, it can be concluded that a strong absorption diminishes the light intensity and the sampling points on the ringdown curve, thus reducing the SNR, which is consistent with the conjecture of Figure 4. The ringdown time of the empty cavity is slightly less than $66.7 \mu \mathrm{s}$, which could be due to the slight presence of pollutants on the surface of the cavity mirror. 

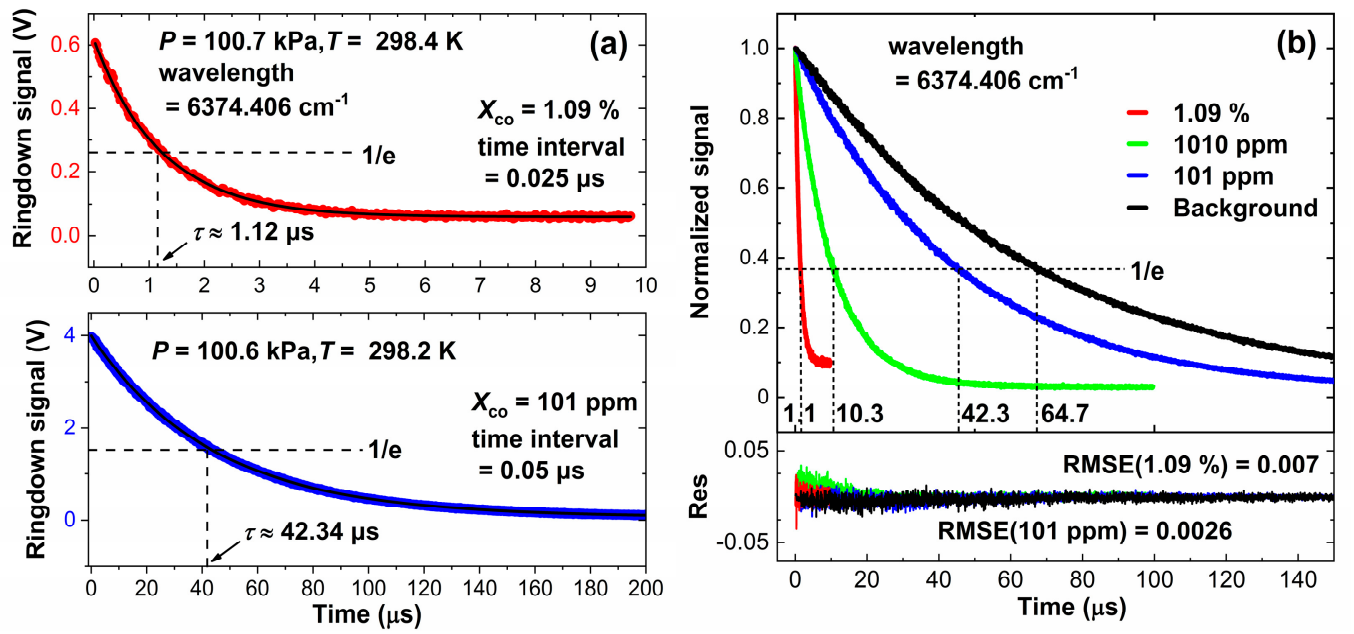

Figure 7. (a) Ringdown signals at different concentrations and (b) normalized ringdown signals and fitting residuals.

\section{Results and Discussion of the Wide Range and Calibration-Free Technique}

Figure 8a shows the measuring range and accuracy of CW-CRDS and WM-DAS at different concentrations. For each method, the measurement over $30 \mathrm{~min}$, revealed that the fluctuation of ambient temperature was less than $0.2 \mathrm{~K}$, and the concentration of $\mathrm{CO}$ ranged from $4 \mathrm{ppm}$ to $1.09 \%$. The standard deviation corresponds to the measurement accuracy [26]. Allowing for the regional division in Figure 4, Figure 8b shows the typical 1.09\%, 3650 ppm, and 101 ppm measurements, all of which show good Gaussian distributions. The two methods have the same measurement accuracy between $101 \mathrm{ppm}$ and $3650 \mathrm{ppm}$. When the concentration is higher than $3650 \mathrm{ppm}$, the accuracy of WM-DAS becomes increasingly better. Conversely, when the concentration is less than $101 \mathrm{ppm}$, the accuracy of CW-CRDS is better. These experimental results further validate the inference from Figure 4.

(a)

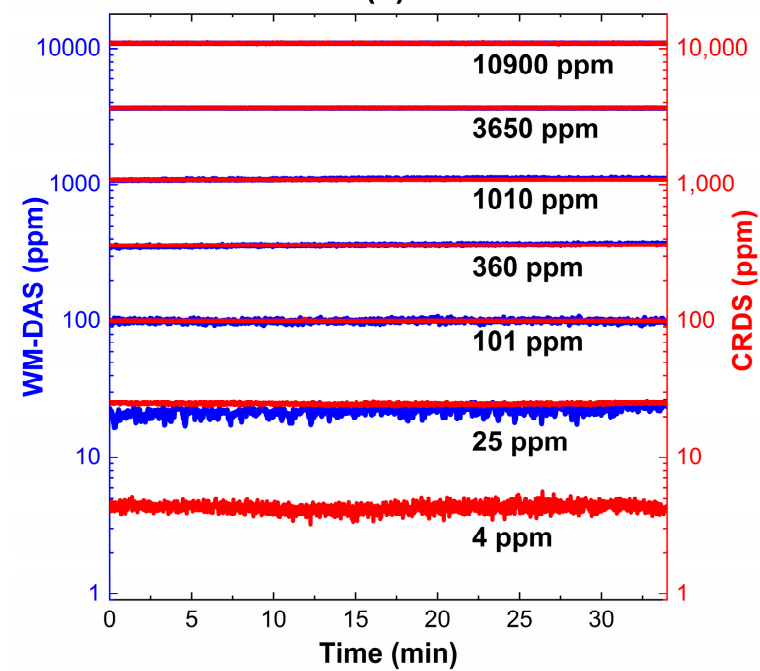

(b)
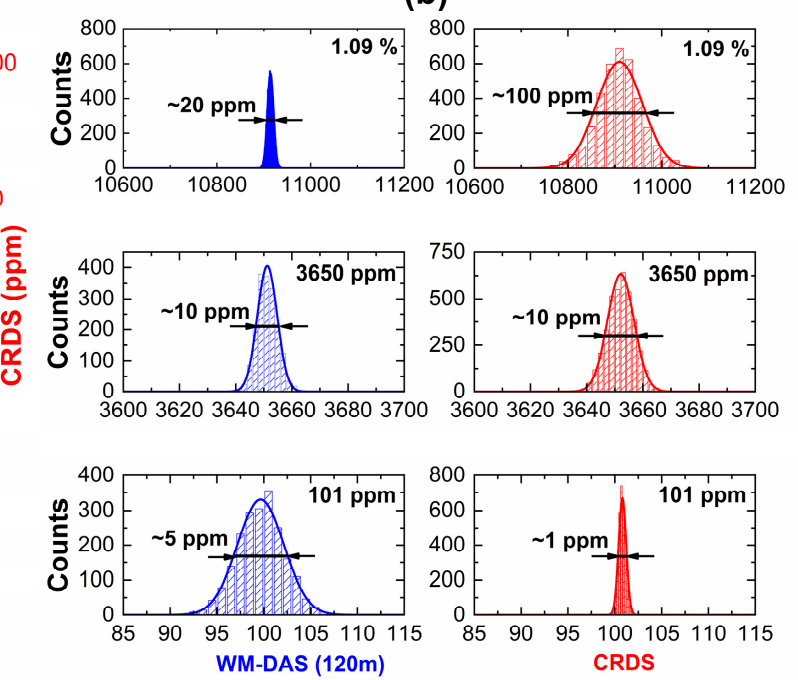
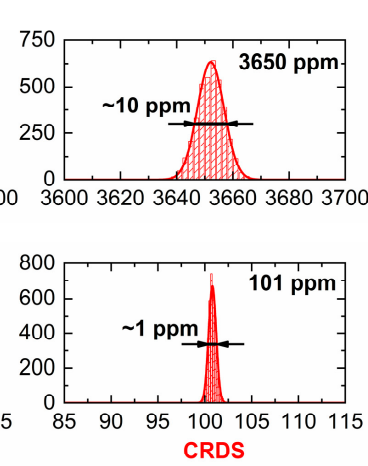

Figure 8. (a) The results of long-term measurement by WM-DAS and CW-CRDS at different concentrations and (b) histogram of the measured data and the best fits of Gaussian profile, and FWHM (equal to 2.355 times the standard deviation) of Gaussian profile.

According to Equation (6), the baseline ringdown time, $\tau_{0}$, can be calculated directly without the need to measure the empty cavity. As shown in Figure 9a, the measurement accuracy of both methods 
is high in the 360-3650 ppm range, which implies their suitability for calculating $\tau_{0}$. Figure $9 \mathrm{~b}$ displays the relationship between $(c \tau)^{-1}$ (measured by CW-CRDS at center wavelength) and $\kappa$ (measured by WM-DAS, where $\kappa=\alpha / L)$. These data show a good degree of linearity of 0.99998 and the slope (0.99989) is almost equal to one, which is in good agreement with the Equation (6). In addition, $\tau_{0}$ can be obtained from the intercept $\left(c \tau_{0}\right)^{-1}$ which can, in turn, be obtained by the linear fitting of these data. The calculated $\tau_{0}$ is $64.74(4) \mu \mathrm{s}$.
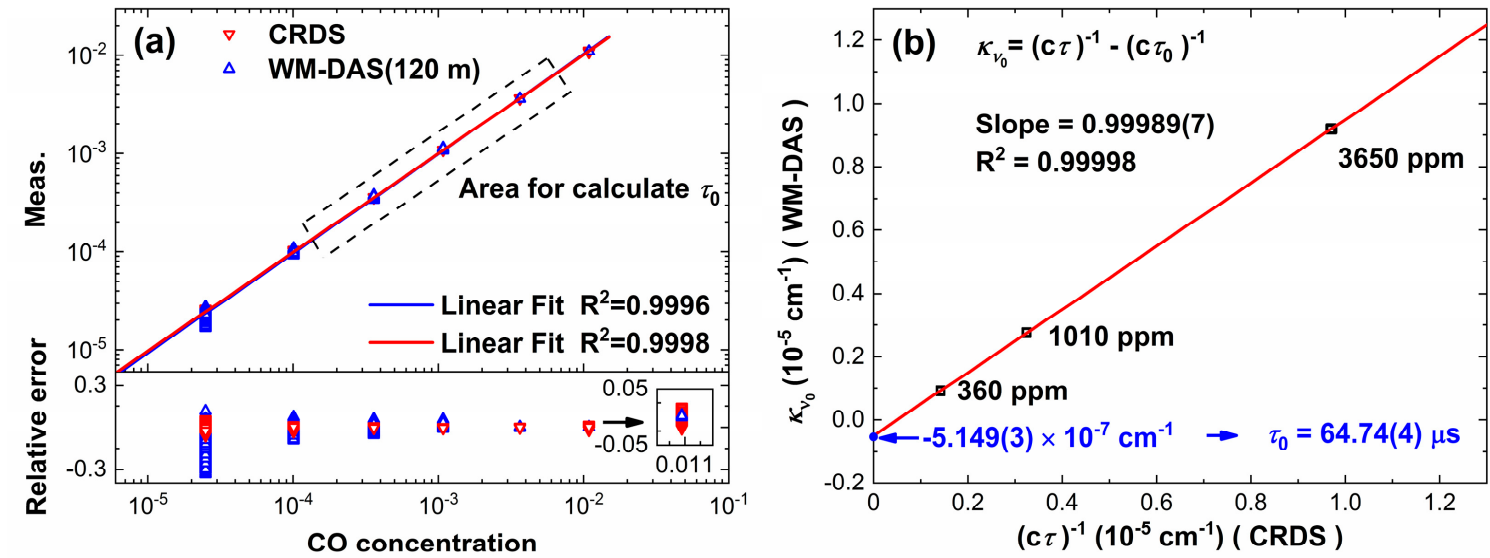

Figure 9. (a) Measurement results of CW-CRDS and WM-DAS and their relative errors with standard concentrations and $(\mathbf{b})$ use of overlapping regions in the two methods to calculate $\tau_{0}$.

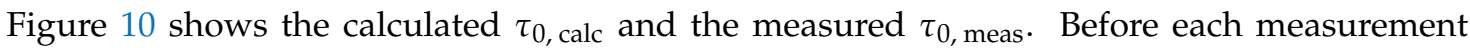
displayed in Figure 8a, the cavity was purged with nitrogen (purity 99.999\%) for $\sim 5$ min, followed by the baseline ringdown time $\tau_{0 \text {, meas }}$ measurement which was averaged after the intra-cavity pressure became stable. The standard deviation between the measured $\tau_{0 \text {, meas }}$ and the calculated $\tau_{0 \text {, calc values }}$ is about $0.007 \mu$ s (relative error is $1.08 \times 10^{-4}$ ), which implies that the calculated value $\tau_{0 \text {, calc }}$ is closer to the average value of $\tau_{0, \text { meas }}$.
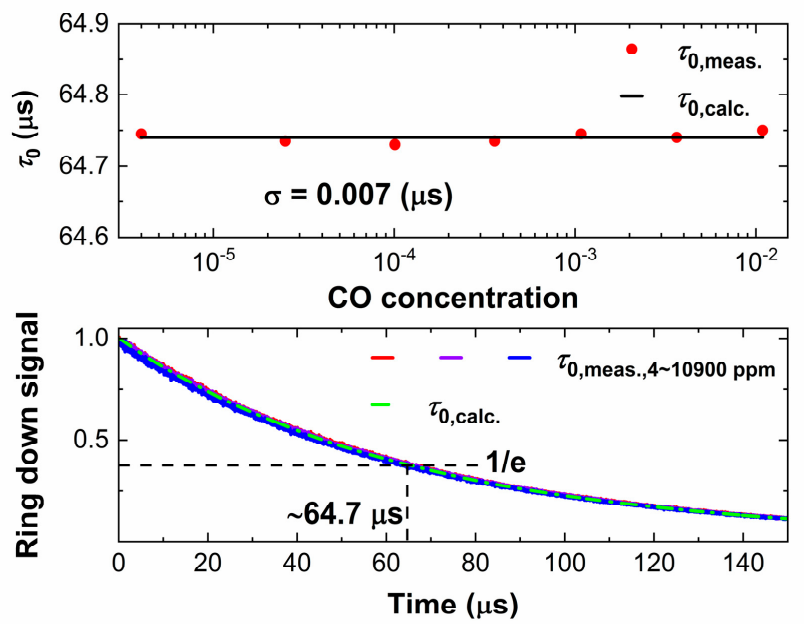

Figure 10. Measured and calculated values of $\tau_{0}$.

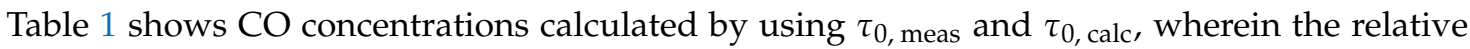
errors are less than $4 \times 10^{-4}$. These results confirm that the gas concentration can be accurately

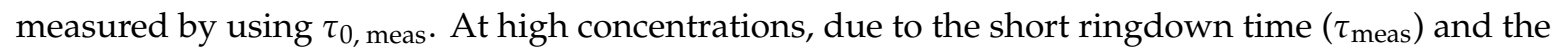
weak ringdown signal, the SNR is low and the error between the measured concentration $\left(X_{\text {meas. }}\right.$ and $X_{\text {calc. }}$ ) and $X_{\mathrm{CO}}$ can reach up to $\sim 10 \mathrm{ppm}$. It is worth noting that in real-time poor industrial field measurements, $\tau_{0}$ will attenuate slowly due to the pollution on the mirror surface [10-12,17-19]. 
However, following the present work, $\tau_{0}$ can be obtained by linear fitting of $(c \tau)^{-1}$ and $\kappa$, which is beneficial for the development of simple, fast, and calibration-free gas sensors.

Table 1. CO concentration obtained by $\tau_{0}$, meas. and $\tau_{0}$, calc.

\begin{tabular}{ccccccc}
\hline $\begin{array}{c}\boldsymbol{X}_{\mathbf{C O}} \\
{[\mathbf{p p m}]}\end{array}$ & $\begin{array}{c}\boldsymbol{\tau}_{\text {meas }} \\
{[\boldsymbol{\mu} \mathbf{s}]}\end{array}$ & $\begin{array}{c}\boldsymbol{\tau}_{\mathbf{0 , m e a s}} \\
{[\boldsymbol{\mu} \mathbf{s}]}\end{array}$ & $\begin{array}{c}\boldsymbol{X}_{\text {meas }} \\
{[\mathbf{p p m ]}]}\end{array}$ & $\begin{array}{c}\boldsymbol{\tau}_{\mathbf{0 , \text { calc }}} \\
{[\boldsymbol{\mu \mathbf { s } ]}]}\end{array}$ & $\begin{array}{c}\boldsymbol{X}_{\text {calc }} \\
{[\mathbf{p p m ]}]}\end{array}$ & $\begin{array}{c}\boldsymbol{R E} \\
{\left[\mathbf{1 0}^{-\mathbf{6}}\right]}\end{array}$ \\
\hline 10,900 & 1.12 & 64.75 & $10,909.55$ & & $10,909.52$ & 2.75 \\
3650 & 3.22 & 64.74 & 3652.02 & & 3652.02 & 0.00 \\
1010 & 10.28 & 64.75 & 1011.14 & 64.74 & 1011.12 & 19.78 \\
360 & 22.45 & 64.73 & 359.31 & & 359.34 & 83.49 \\
101 & 42.34 & 64.74 & 100.90 & & 100.92 & 198.02 \\
25 & 57.68 & 64.75 & 25.12 & & 25.11 & 398.09 \\
\hline
\end{tabular}

Note: $X_{\text {meas. }}$ denotes the concentration obtained by $\tau_{0 \text {, meas }} ; X_{\text {calc }}$. denotes the concentration obtained by $\tau_{0 \text {, meas. }}$; $X_{\mathrm{CO}}$, standard $\mathrm{CO}$ concentration; and $R E$ denotes the relative errors between the $X_{\text {meas. }}$ and $X_{\text {calc. }}$.

To further compare the two spectroscopic techniques, a calculation of the Allan deviation [36] for a simultaneously measured concentration of $101 \mathrm{ppm}$ was conducted under identical conditions (Figure 11). At the integration time of $25 \mathrm{~s}$, the detection limit of CW-CRDS reaches $35 \mathrm{ppb}$ which is equivalent to that found in the literature $[37,38]$ and for WM-DAS it is $161 \mathrm{ppb}$ which is comparable to WMS $[39,40]$ and is five times greater than that of CW-CRDS. The Allan deviation also indicates that the lowest stable precision for CW-CRDS needs less averaging time which is much less than the WM-DAS. After $100 \mathrm{~s}$, the averages of both of the measurements show a similarly unstable deviation. This could be caused by the drifts in temperature, pressure, and cavity length for WM-DAS [29-31]. For CW-CRDS, this could be affected by laser wavelength drift, temperature, pressure and other factors [10-12].

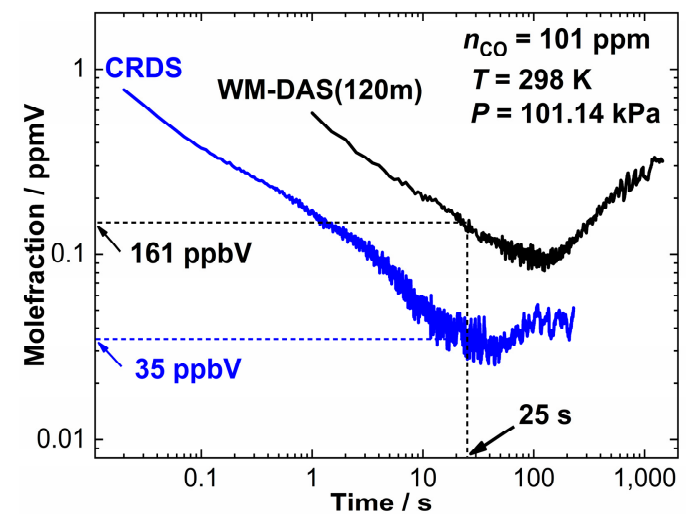

Figure 11. Allan standard deviation of two methods at $101 \mathrm{ppm}$.

\section{Conclusions}

This paper presents the construction of a wide range and calibration-free spectrometer based on the combination of WM-DAS and CW-CRDS methods to measure gas concentrations. The measuring range and accuracy of WM-DAS and CW-CRDS are analyzed in detail and verified by using a mixture of $\mathrm{CO}$ and $\mathrm{N}_{2}$ in various proportions and concentrations. The measurement accuracy for $3650 \mathrm{ppm} \sim 1.09 \%$, 101 3650 ppm, and 4 101 ppm ranges are $5 \sim 10$ ppm, 0.5 5 ppm, and $\sim 0.5$ ppm, respectively. In the range 101 3650 ppm, the baseline ringdown time, $\tau_{0}$, is calculated by using the absorbance measured by WM-DAS and the ringdown time with gas absorption at central frequency. The relative error between the calculated and the measured $\tau_{0}$ is less than $4 \times 10^{-4}$. The gas concentration can be quantified by measuring the ringdown time at the center frequency without measuring $\tau_{0}$. Combining the advantages of WM-DAS and CW-CRDS, a wide and continuous range (more than five orders of magnitude), high precision, and fast $(0.1 \mathrm{~ms})$ spectrometer is constructed. The detection limit of 
this system can reach $35 \mathrm{ppb}$ in $25 \mathrm{~s}$. With increased precision and SNR, the range and speed of the measurements can become wider and faster, which offers a new possibility for its usability as a gas sensor in the industrial field.

Author Contributions: Conceptualization, Z.W. and Z.P.; writing-review and editing, Z.W.; supervision, Y.D. (Yanjun Ding) and Y.D. (Yanjun Du). All authors have read and agreed to the published version of the manuscript.

Funding: This research was funded by the National Natural Science Foundation of China (NSFC) (no. 51676105, no. 11972213, and no. 51906120) and the National Key R\&D Program of China (no. 2016YFC0201104).

Conflicts of Interest: The authors declare no conflict of interest.

\section{References}

1. Adámek, P.; Olejníček, J.; Čada, M.; Kment, Š.; Hubička, Z. Time-resolved tunable diode laser absorption spectroscopy of pulsed plasma. Opt. Lett. 2013, 38, 2428-2430. [CrossRef] [PubMed]

2. Goldenstein, C.S.; Spearrin, R.M.; Jeffries, J.B.; Hanson, R.K. Infrared laser-absorption sensing for combustion gases. Prog. Energy Combust. 2017, 60, 132-176. [CrossRef]

3. Witzel, O.; Klein, A.; Meffert, C.; Schulz, C.; Kaiser, S.A.; Ebert, V. Calibration-free, high-speed, in-cylinder laser absorption sensor for cycle-resolved, absolute $\mathrm{H}_{2} \mathrm{O}$ measurements in a production IC engine. Proc. Combust. Inst. 2015, 35, 3653-3661. [CrossRef]

4. McManus, J.B.; Zahniser, M.S.; Nelson, D.D.; Shorter, J.H.; Herndon, S. Wood E Application of quantum cascade lasers to high-precision atmospheric trace gas measurements. Opt. Eng. 2010, 49, 111124. [CrossRef]

5. McManus, J.B.; Zahniser, M.S.; Nelson, D.D.; Shorter, J.H.; Herndon, S.; Jervis, D.; Agnese, M.; McGovern, R.; Yacovitch, T.I.; Roscioli, J.R. Recent progress in laser-based trace gas instruments: Performance and noise analysis. Appl. Phys. B 2015, 119, 203-218. [CrossRef]

6. Zhao, G.; Tan, W.; Jia, M.; Hou, J.; Ma, W.; Dong, L.; Zhang, L.; Feng, X.; Wu, X.; Yin, W.; et al. Intensitystabilized fast-scanned direct absorption spectroscopy instrumentation based on a distributed feedback laser with detection sensitivity down to $4 \times 10^{-6}$. Sensors 2016, 16, 1544. [CrossRef]

7. Wojtas, J.; Mikolajczyk, J.; Bielecki, Z. Aspects of the Application of Cavity Enhanced Spectroscopy to Nitrogen Oxides Detection. Sensors 2013, 13, 7570-7598. [CrossRef]

8. Arslanov, D.D.; Cristescu, S.M.; Harren, F.J.M. Optical parametric oscillator based off-axis integrated cavity output spectroscopy for rapid chemical sensing. Opt. Lett. 2010, 35, 3300-3302. [CrossRef]

9. Moyer, E.J.; Sayres, D.S.; Engel, G.S.; St. Clair, J.M.; Keutsch, F.N.; Allen, N.T.; Kroll, J.H.; Anderson, J.G. Design considerations in high-sensitivity off-axis integrated cavity output spectroscopy. Appl. Phys. B 2008, 92, 467-474. [CrossRef]

10. Romanini, D.; Kachanov, A.A.; Sadeghi, N.; Stoeckel, F. CW cavity ring down spectroscopy. Chem. Phys. Lett. 1997, 264, 316-322. [CrossRef]

11. Bucher, C.R.; Lehmann, K.K.; Plusquellic, D.F; Fraser, G.T. Doppler-free nonlinear absorption in ethylene by use of continuous-wave cavity ring down spectroscopy. Appl. Opt. 2000, 39, 3154-3164. [CrossRef] [PubMed]

12. Dudek, J.B.; Tarsa, P.B.; Velasquez, A.; Wladyslawski, M.; Rabinowitz, P.; Lehmann, K.K. Trace moisture detection using continuous-wave cavity ring-down spectroscopy. Anal. Chem. 2003, 75, 4599-4605. [CrossRef] [PubMed]

13. Karion, A.; Sweeney, C.; Wolter, S.; Newberger, T.; Chen, H.; Andrews, A.; Kofler, J.; Neff, D.; Tans, P. Long-term greenhouse gas measurements from aircraft. Atmos. Meas. Tech. 2013, 6, 511-526. [CrossRef]

14. Wagner, S.; Klein, M.; Kathrotia, T.; Riedel, U.; Kissel, T.; Dreizler, A.; Ebert, V. Absolute, spatially resolved, in situ CO profiles in atmospheric laminar counter-flow diffusion flames using $2.3 \mu \mathrm{m}$ TDLAS. Appl. Phys. $B$ 2012, 109, 533-540. [CrossRef]

15. Diemel, O.; Honza, R.; Ding, C.P.; Böhm, B.; Wagner, S. In situ sensor for cycle-resolved measurement of temperature and mole fractions in IC engine exhaust gases. Proc. Combust. Inst. 2019, 37, 1453-1460. [CrossRef]

16. Gianella, M.; Reuter, S.; Press, S.A.; Schmidt-Bleker, A.; van Helden, J.H.; Ritchie, G.A.D. $\mathrm{HO}_{2}$ reaction kinetics in an atmospheric pressure plasma jet determined by cavity ring-down spectroscopy. Plasma Sources Sci. Technol. 2018, 27, 095013. [CrossRef] 
17. Long, D.A.; Fleisher, A.J.; Liu, Q.; Hodges, J.T. Ultra-sensitive cavity ring down spectroscopy in the mid-infrared spectral region. Opt. Lett. 2016, 41, 1612-1615. [CrossRef]

18. Karhu, J.; Lehmann, K.; Vainio, M.; Metsälä, M.; Halonen, L. Step-modulated decay cavity ring-down detection for double resonance spectroscopy. Opt. Express 2018, 26, 29086-29098. [CrossRef]

19. McHale, L.E.; Hecobian, A.; Yalin, A.P. Open-path cavity ring-down spectroscopy for trace gas measurements in ambient air. Opt. Express 2016, 24, 5523-5535. [CrossRef]

20. Robert, C. Simple, stable, and compact multiple-reflection optical cell for very long optical paths. Appl. Opt. 2007, 46, 5408-5418. [CrossRef]

21. Pal, M.; Maity, A.; Pradhan, M. A continuous-wave quantum cascade laser near $7.5 \mu \mathrm{m}$ combined with 2f-wavelength modulation spectroscopy for trace monitoring of ambient $\mathrm{CH}_{4}$ concentrations. Laser Phys. 2018, 28, 105702. [CrossRef]

22. Kostinek, J.; Roiger, A.; Davis, K.J.; Sweeney, C.; DiGangi, J.P.; Choi, Y.; Baier, B.; Hase, F.; Groß, J.; Eckl, M.; et al. Adaptation and performance assessment of a quantum and interband cascade laser spectrometer for simultaneous airborne in situ observation of $\mathrm{CH}_{4}, \mathrm{C}_{2} \mathrm{H}_{6}, \mathrm{CO}_{2}, \mathrm{CO}$ and $\mathrm{N}_{2} \mathrm{O}$. Atmos. Meas. Tech. 2019, 12, 1767-1783. [CrossRef]

23. Stewart, G.; Johnstone, W.; Bain, J.; Ruxton, K.; Duffin, K. Recovery of absolute gas absorption line shapes using tunable diode laser spectroscopy with wavelength modulation-part 1: Theoretical analysis. J. Lightwave Technol. 2011, 29, 811-821.

24. Peng, Z.M.; Ding, Y.J.; Jia, J.W.; Lan, L.J.; Du, Y.J.; Li, Z. First harmonic with wavelength modulation spectroscopy to measure integrated absorbance under low absorption. Opt. Express 2013, 21, 23724-23735.

25. Lan, L.J.; Ding, Y.J.; Peng, Z.M.; Du, Y.J.; Liu, Y.F.; Li, Z. Multi-harmonic measurements of line shape under low absorption conditions. Appl. Phys. B 2014, 117, 543-547. [CrossRef]

26. Klein, A.; Witzel, O.; Ebert, V. Rapid, Time-Division Multiplexed, Direct Absorption- and Wavelength Modulation-Spectroscopy. Sensors 2014, 14, 21497-21513. [CrossRef]

27. Womack, C.C.; Neuman, J.A.; Veres, P.R.; Eilerman, S.J.; Brock, C.A.; Decker, Z.C.J.; Zarzana, K.J.; Dube, W.P.; Wild, R.J.; Wooldridge, P.J.; et al. Evaluation of the accuracy of thermal dissociation CRDS and LIF techniques for atmospheric measurement of reactive nitrogen species. Atmos. Meas. Tech. 2017, 10, 1911-1926. [CrossRef]

28. Li, Z.Y.; Hua, R.Z.; Xie, P.H.; Wang, H.C.; Lu, K.D.; Wang, D. Intercomparison of in situ CRDS and CEAS for measurements of atmospheric $\mathrm{N}_{2} \mathrm{O}_{5}$ in Beijing, China. Sci. Total Environ. 2018, 613-614, 131-139. [CrossRef]

29. Du, Y.J.; Peng, Z.M.; Ding, Y.J. Wavelength modulation spectroscopy for recovering absolute absorbance. Opt. Express 2018, 26, 9263-9272. [CrossRef]

30. Li, J.D.; Du, Y.J.; Peng, Z.M.; Ding, Y.J. Measurements of spectroscopic parameters of $\mathrm{CO}_{2}$ transitions for Voigt, Rautian, galatry and speed-dependent voigt profiles near $1.43 \mu \mathrm{m}$ using the WM-DAS method. J. Quant. Spectrosc. Radiat. Transf. 2019, 224, 197-205. [CrossRef]

31. Du, Y.J.; Peng, Z.M.; Ding, Y.J. High-accuracy sinewave-scanned direct absorption spectroscopy. Opt. Express 2018, 26, 29550-29560. [CrossRef] [PubMed]

32. Engel, G.S.; Moyer, E.J. Precise multipass Herriott cell design: Derivation of controlling design equations. Opt. Lett. 2007, 32, 704-706. [CrossRef] [PubMed]

33. Mazurenka, M.; Wada, R.; Shillings, A.J.L.; Butler, T.J.A.; Beames, J.M.; Orr-Ewing, A.J. Fast Fourier transform analysis in cavity ring-down spectroscopy: Application to an optical detector for atmospheric $\mathrm{NO}_{2}$. Appl. Phys. B 2005, 81, 135-141. [CrossRef]

34. Goldenstein, C.S.; Hanson, R.K. Diode-laser measurements of linestrength and temperature-dependent lineshape parameters for $\mathrm{H}_{2} \mathrm{O}$ transitions near $1.4 \mu \mathrm{m}$ using Voigt, Rautian, Galatry, and speed-dependent Voigt profiles. J. Quant. Spectrosc. Radiat. Transf. 2015, 152, 127-139. [CrossRef]

35. McManus, J.B.; Zahniser, M.S.; Nelson, D.D. Dual quantum cascade laser trace gas instrument with astigmatic Herriott cell at high pass number. Appl. Opt. 2011, 50, A74-A85. [CrossRef]

36. Allan, D.W. Statistics of Atomic Frequency Standards. Proc. IEEE 1966, 54, 221-230. [CrossRef]

37. Reed, Z.D.; Hodges, J.T. Line shape parameters of helium-broadened ${ }^{12} \mathrm{C}^{16} \mathrm{O}$ transitions in the $3 \rightarrow 0$ overtone band near $1.57 \mu \mathrm{m}$. J. Quant. Spectrosc. Radiat. Transf. 2017, 203, 300-308. [CrossRef]

38. Ngo, N.H.; Lin, H.; Hodges, J.T.; Trand, H. Spectral shapes of rovibrational lines of CO broadened by He, Ar, $\mathrm{Kr}$ and $\mathrm{SF}_{6}$ : A test case of the Hartmann-Tran profile. J. Quant. Spectrosc. Radiat. Transf. 2017, 203, 325-333. [CrossRef] 
39. Cai, T.D.; Gao, G.Z.; Chen, W.D.; Liu, G.; Gao, X.M. Simultaneous Measurements of $\mathrm{CO}_{2}$ and CO Using a Single Distributed-Feedback (DFB) Diode Laser Near $1.57 \mu \mathrm{m}$ at Elevated Temperatures. Appl. Spectrosc. 2011, 65, 108-112. [CrossRef]

40. Li, J.S.; Deng, H.; Sun, J.; Yu, B.L.; Fischer, H. Simultaneous atmospheric $\mathrm{CO}, \mathrm{N}_{2} \mathrm{O}$ and $\mathrm{H}_{2} \mathrm{O}$ detection using a singlequantum cascade laser sensor based on dual-spectroscopy techniques. Sensor Actuat. B Chem. 2016, 231, 723-732. [CrossRef]

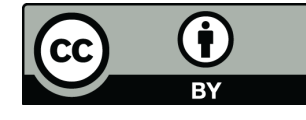

(C) 2020 by the authors. Licensee MDPI, Basel, Switzerland. This article is an open access article distributed under the terms and conditions of the Creative Commons Attribution (CC BY) license (http://creativecommons.org/licenses/by/4.0/). 